\title{
Pengaruh Obat Antihipertensi terhadap Disfungsi Ereksi
}

\author{
Stela G. Amrin, ${ }^{1}$ Lydia E. N. Tendean, ${ }^{2}$ Grace L. A. Turalaki $^{2}$
}

\author{
1Program Studi Pendidikan Dokter Fakultas Kedokteran Universitas Sam Ratulangi, \\ Manado, Indonesia. \\ ${ }^{2}$ Bagian Biologi Fakultas Kedokteran Universitas Sam Ratulangi, Manado, Indonesia \\ Email: stelaamrin1999@gmail.com
}

\begin{abstract}
Erectile dysfunction (ED) is a condition where intercourse is not interrupted due to the inability of the penis to achieve a penile erection. One of the drugs that can affect erectile dysfunction are drugs for hypertension therapy, namely diuretics and $\beta$-blockers, except for nebivolol and clonidine. The purpose of this study was to determine the effect of antihypertensive drugs on erectile dysfunction. This study was in the form of a literature review by searching data using three databases namely ScienceDirect, Pubmed and Google Scholar. The keywords used were antihypertensive drugs AND erectile dysfunction. After being selected based on inclusion and exclusion criteria, there were 12 literature consisting of 4 randomized controlled trials, 3 cross-sectional studies, 2 cohort studies and 1 case control study. The research shows that 3 out of 5 literature states that there is an effect of diuretic antihypertensive drugs on the occurrence of erectile dysfunction, while 6 out of 9 literature states that there is no effect of $\beta$-blocker antihypertensive drugs on the occurrence of erectile dysfunction. In conclusion, diuretic and $\beta$-blocker as antihypertensive drugs have an effect on erectile dysfunction. Diuretic antihypertensive drugs have more impact on erectile dysfunction compared to $\beta$-blocker antihypertensive drugs.
\end{abstract}

Keywords: Antihypertensive drugs, erectile dysfunction

\begin{abstract}
Abstrak: Disfungsi ereksi (DE) adalah keadaan terganggunya hubungan seksual akibat ketidakmampuan penis dalam mencapai ereksi penis. Salah satu obat yang dapat mempengaruhi disfungsi ereksi yaitu obat untuk terapi hipertensi yaitu golongan diuretik dan golongan $\beta$-blocker kecuali nebivolol dan klonidin. Tujuan penelitian ini adalah untuk mengetahui pengaruh obat antihipertensi terhadap disfungsi ereksi. Penelitian ini dalam bentuk literature review dengan pencarian data menggunakan tiga database yaitu ScienceDirect, Pubmed dan Google Cendekia. Kata kunci yang digunakan yaitu obat antihipertensi DAN disfungsi ereksi. Setelah diseleksi berdasarkan kriteria inklusi dan eksklusi didapatkan 12 literatur yang terdiri dari 4 randomized controlled trial, 3 crosssectional study, 2 cohort study dan 1 case control study. Dari penelitian menunjukkan bahwa 3 dari 5 literatur menyebutkan terdapat pengaruh obat antihipertensi golongan diuretik terhadap terjadinya disfungsi ereksi, sedangkan 6 dari 9 literatur menyebutkan tidak terdapat pengaruh obat antihipertensi golongan $\beta$-blocker terhadap terjadinya disfungsi ereksi. Sebagai simpulan, obat antihipertensi golongan diuretik dan $\beta$-blocker memiliki pengaruh terhadap disfungsi ereksi. Obat antihipertensi golongan diuretik lebih berpengaruh terhadap disfungsi ereksi dibandingkan dengan obat antihipertensi golongan $\beta$-blocker.
\end{abstract}

Kata Kunci: Obat antihipertensi, disfungsi ereksi

\section{PENDAHULUAN}

Disfungsi ereksi (DE) adalah keadaan terganggunya hubungan seksual akibat ketidakmampuan penis dalam mencapai ereksi penis. ${ }^{1,2}$ Disfungsi ereksi menjadi suatu masalah bagi pasangan suami istri akibat ketidakmampuan memuaskan 
pasangan yang berpengaruh dalam keharmonisan rumah tangga. ${ }^{3}$

Faktor risiko yang terkait dengan disfungsi ereksi yaitu vaskular, neurogenik, struktural, hormonal, psikogenik atau induksi obat-obatan dan trauma. ${ }^{4,5}$ Beberapa obat yang dapat mempengaruhi disfungsi ereksi yaitu obat antikolinergik, psikotropika dan obat untuk terapi hipertensi yaitu golongan diuretik dan golongan $\beta$-blocker kecuali nebivolol dan klonidin. ${ }^{6}$

Data penelitian menunjukkan bahwa disfungsi seksual lebih sering ditemui pada pasien hipertensi dibandingkan pada pasien normotensi. Berdasarkan data yang diperoleh dari studi observasi menunjukkan prevalensi disfungsi ereksi yang diobati lebih tinggi daripada pasien hipertensi yang tidak diobat. $^{7}$

Tingkat kejadian disfungsi ereksi pada pasien yang mengonsumsi obat antihipertensi adalah 14\%. ${ }^{6}$ Prevalensi disfungsi ereksi di Indonesia belum diketahui secara tepat, diperkirakan $16 \%$ laki-laki usia 20-75 tahun mengalami disfungsi ereksi. ${ }^{8}$

Data epidemiologi menunjukan bahwa disfungsi ereksi memiliki angka yang tinggi di seluruh dunia. Pada tahun 1995, disfungsi ereksi diperkirakan dialami oleh 152 juta pria di seluruh dunia dan diperkirakan pada 2025 akan mencapai jumlah 322. Meningkatnya jumlah prevalensi disfungsi ereksi dengan mengikuti bertambahnya usia. ${ }^{9}$ Hampir $40 \%$ pria dengan usia di atas 40 tahun menderita disfungsi ereksi dengan memiliki tingkat keparahan yang bermacam-macam. ${ }^{2}$ Berdasarkan data Massachusetts Male Aging Study (MMAS), diprediksi sekitar 17.781 kasus baru disfungsi ereksi di Massachusetts dan sekitar 617.715 kasus di Amerika Serikat setiap tahun. ${ }^{10}$ Data yang di dapat dari penelitian di Australia, AS dan Inggris serupa, memperkirakan prevalensi disfungsi ereksi sekitar 5\% di antara usia 40 tahun, $10 \%$ di antara pria berusia 60 -an, $15 \%$ di antara pria berusia 70-an dan 30-40\% di antara pria berusia 80-an. ${ }^{11}$
Disfungsi ereksi merupakan masalah yang dialami oleh banyak pria di dunia, Data hasil survei di Indonesia pada pria usia 40-80 tahun, 52\% berpendapat bahwa kehidupan seks penting. ${ }^{3}$

\section{METODE PENELITIAN}

Penelitian ini dilakukan dengan metode literature review yang dilakukan dengan cara identifikasi, evaluasi dan interpretasi terhadap semua hasil penelitian tertentu yang bisa didapat dari berbagai sumber seperti jurnal, buku, internet dan pustaka lain. Penelitian ini dilakukan pada bulan September - Desember 2020 di Perpustakaan Virtual.

Sumber data pada penelitian ini merupakan data sekunder, dengan pembatasan kriteria inklusi merupakan artikel, jurnal dan dokumen skripsi terbitan 10 tahun terakhir (2011-2020), menggunakan bahasa indonesia dan bahasa Inggris dan pembahasan mengacu pada pengguna obat antihipertensi, yaitu duretik dan $\beta$-blocker. Sedangkan Kriteria Eksklusi sendiri yaitu sampel penelitian pria yang berusia $>80$ tahun dan tidak tersedia format full-text maupun jurnal yang dipublikasikan.

Data dikumpulkan dengan cara mengakses secara daring database dari Science Direct, Pubmed dan Google Cendekia. Pencarian data menggunakan beberapa kata kunci yang ditentukan, yaitu "obat antihipertensi" DAN "disfungsi ereksi" dan "antihypertensive drugs" AND "erectile dysfunction", baik yang bahasa indonesia atau bahasa inggris.

Literatur yang didapatkan dari tiga database yang digunakan berjumlah 1.202 dari Science Direct, 175 dari Pubmed dan 217 dari Google Cendekia $(\mathrm{n}=1594)$ sesuai dengan kata kunci yang telah ditentukan. Hasil pencarian disaring berdasarkan judul dan abstrak yang sesuai dengan topik pembahasan, demikian juga dengan literatur yang sama yang terdapat di database yang berbeda hanya dihitung satu literatur hingga didapat 22 dari Science Direct, 47 Pubmed dan tidak ada literatur yang didapatkan dari Google Cendekia 
$(n=69)$. Selanjutnya literatur disaring kembali berdasarkan kriteria inklusi dan eksklusi, yang akhirnya didapatkan 10 literatur untuk digunakan dalam penelitian ini.

\section{HASIL PENELITIAN}

Sepuluh literatur memenuhi kriteria inklusi dan eksklusi yang telah ditentukan yang kemudian dipilih menjadi sumber data penelitian ini (Tabel 1). Empat dari sepuluh literatur menggunakan desain studi randomized controlled trial, tiga literatur menggunakan desain studi cross-sectional, dua literatur menggunakan desain studi cohort dan satu literatur menggunakan case control

Tiga literatur secara langsung membahas topik obat antihipertensi yaitu $\beta$-blocker dan disfungsi ereksi. Tiga literatur membahas tekanan darah dan disfungsi ereksi. Satu literatur membahas disfungsi seksual dan gagal jantung sistolik. Satu literatur membahas perubahan aktivitas seksual setelah kejadian jantung. Satu literatur membahas disfungsi ereksi pada pasien dialisis. Satu artikel membahas tentang glaukoma dan disfungsi ereksi.

Lima literatur menggunakan obat antihipertensi $\beta$-blocker. Empat literatur menggunakan obat antihipertensi $\beta$-blocker dan diuretik. Satu literatur menggunakan obat antihipertensi diuretik.

\section{BAHASAN Diuretik}

Berdasarkan hasil dari penelitian literatur-literatur yang direview, menunjukkan bahwa 3 dari 5 literatur terdapat pengaruh obat antihipertensi golongan diuretik terhadap terjadinya disfungsi ereksi. Penelitian Mohammadi SZ tahun 2012 pada 100 pasien pria dengan gagal jantung sistolik dengan usia rata-rata 59 tahun menemukan adanya hubungan antara pasien gagal jantung dirawat dengan obat diuretik ditemukan memiliki disfungsi seksual yang lebih parah. Disfungsi ereksi menunjukkan skor yang secara signifikan sehubungan dengan konsumsi dan diuretik
$(\mathrm{P}=0.035) .{ }^{16}$ Penelitian Steinke EE tahun 2015 pada 149 pasien pria dengan usia ratarata 66, mayoritas sampel menggunakan tembakau saat ini atau sebelumnya dan memiliki indeks massa tubuh rata-rata 29. Diuretik secara signifikan berkontribusi terhadap perubahan aktivitas seksual $(\mathrm{p}=0.018)$ dan khususnya untuk diuretik loop $(\mathrm{p}=0.007)$. Dalam kedua kasus tersebut, pasien yang melaporkan perubahan dalam aktivitas seksual cenderung melakukan hubungan seks lebih jarang dari sebelumnya atau tidak aktif secara seksual sebelum di diagnosa jantung atau saat ini. Diuretik loop ditemukan secara signifikan berkontribusi pada perubahan aktivitas seksual dan saat ini dilaporkan bahwa lebih banyak pasien yang menggunakan diuretik loop dibandingkan dengan tiazid dan diuretik hemat kalium. ${ }^{17}$

Hasil penelitian Sarma AV tahun 2019 pada 692 pasien yang berusia 19- 50 tahun, 451 laki-laki (69\%) dilaporkan menikah, $21 \%$ pria melaporkan merokok sedangkan $46 \%$ melaporkan minum alkohol setidaknya sekali per minggu. Lebih dari $60 \%$ pasien kelebihan berat badan atau obesitas pada awal dengan median BMI berukuran $25,9 \mathrm{~kg} / \mathrm{m} 2$ dan median DCCT / EDIC HbA1c adalah 7,9\% (kisaran 4,413,9). 17 pria $(2,5 \%)$ memenuhi kriteria JNC untuk hipertensi sedangkan $45 \%$ dari kohort pada awal dianggap prehipertensi. Pada penggunaan diuretik tiazid mampu meningkatkan risiko disfungsi ereksi $(\mathrm{RR})=1.05,95 \%(\mathrm{CI})=0.15-7.56) .{ }^{19}$

Penelitian Joseph P tahun 2018 pada 2153 pria dengan usia rata-rata usia 61 tahun menemukan tidak ada perbedaan yang signifikan candesartan + hidroklorotiazid dan disfungsi ereksi ( $p$ $=0.13$ ). Tercapai penurunan LDL yang signifikan serta tekanan darah dengan menggunakan rosuvastatin dan candesartan + hydroklorotiazid. Ditemukan juga bahwa fungsi ereksi tidak terpengaruh. Apalagi terjadi perubahan fungsi ereksi tidak secara langsung, terkait dengan perubahan tekanan darah atau tingkat LDL dalam periode waktu yang sama. ${ }^{12}$ 
Tabel 1. Hasil utama literatur yang digunakan dalam penelitian.

\begin{tabular}{|c|c|c|c|c|c|}
\hline No & Peneliti & $\begin{array}{c}\text { Tempat } \\
\text { Penelitian } \\
\end{array}$ & $\begin{array}{c}\text { Desain } \\
\text { Penelitian }\end{array}$ & Sampel & Rangkuman Hasil \\
\hline & $\begin{array}{l}\text { Joseph P, } \\
2018^{12}\end{array}$ & $\begin{array}{l}\text { Hamilton, } \\
\text { Kanada }\end{array}$ & $\begin{array}{l}\text { Randomized } \\
\text { controlled } \\
\text { trial }\end{array}$ & $\begin{array}{l}2153 \\
\text { pasien } \\
\text { pria }\end{array}$ & $\begin{array}{l}\text { Tidak ada perbedaan yang signifikan } \\
\text { candesartan }+ \text { hidroklorotiazid dan } \\
\text { disfungsi ereksi }(\mathrm{p}=0.13)\end{array}$ \\
\hline & Gur O, $2017^{13}$ & $\begin{array}{l}\text { Tekirdag, } \\
\text { Turki }\end{array}$ & $\begin{array}{l}\text { Randomized } \\
\text { controlled } \\
\text { trial }\end{array}$ & $\begin{array}{l}119 \\
\text { pasien } \\
\text { pria }\end{array}$ & 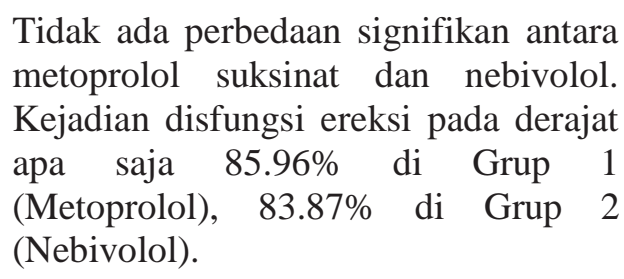 \\
\hline & $\begin{array}{l}\text { Aldemir M, } \\
2015^{14}\end{array}$ & $\begin{array}{l}\text { Izmir, } \\
\text { Turki }\end{array}$ & $\begin{array}{l}\text { Randomized } \\
\text { controlled } \\
\text { trial }\end{array}$ & $\begin{array}{l}60 \\
\text { pasien } \\
\text { pria }\end{array}$ & $\begin{array}{l}\text { Kelompok metoprolol signifikan } \\
(\mathrm{p}<0.001) ; \text { Kelompok nebivolol tidak } \\
\text { signifikan } \mathrm{p}=0.053) .\end{array}$ \\
\hline & $\begin{array}{l}\text { Yang L, } \\
2013^{15}\end{array}$ & $\begin{array}{l}\text { Lanzhou, } \\
\text { China }\end{array}$ & $\begin{array}{l}\text { Randomized } \\
\text { controlled } \\
\text { trial }\end{array}$ & $\begin{array}{l}218 \\
\text { pasien } \\
\text { pria }\end{array}$ & $\begin{array}{l}\text { Tidak ada perubahan signifikan pada } \\
\text { kelompok felodipine }+ \text { metoprolol }(p> \\
0.05) \text {. }\end{array}$ \\
\hline 5. & $\begin{array}{l}\text { Mohammadi } \\
\text { SZ, } \\
2012^{16}\end{array}$ & Karaj, Iran & $\begin{array}{l}\text { Cross- } \\
\text { sectional } \\
\text { study }\end{array}$ & $\begin{array}{l}100 \\
\text { pasien } \\
\text { pria }\end{array}$ & $\begin{array}{l}\text { Disfungsi ereksi menunjukkan skor } \\
\text { signifikan } \beta \text {-blocker }(\mathrm{P}=0.001) \text { dan } \\
\text { diuretik }(\mathrm{P}=0.035) \text {. }\end{array}$ \\
\hline & $\begin{array}{l}\text { Steinke EE, } \\
2015^{17}\end{array}$ & $\begin{array}{l}\text { Kansas, } \\
\text { Amerika } \\
\text { Serikat }\end{array}$ & $\begin{array}{l}\text { Cross- } \\
\text { sectional } \\
\text { study }\end{array}$ & $\begin{array}{l}149 \\
\text { pasien } \\
\text { pria }\end{array}$ & $\begin{array}{l}\text { Secara signifikan } \beta \text {-blocker generasi } \\
\text { pertama }(\mathrm{p}=0.019) \text { dan } \beta \text {-blocker } \\
\text { generasi ketiga signifikan }(\mathrm{p}=0.009) \text {. } \\
\text { Diuretik secara signifikan }(\mathrm{p}=0.018) \\
\text { dan khusus diuretik loop }(\mathrm{p}=0.007) .\end{array}$ \\
\hline & $\begin{array}{l}\text { Seck SM, } \\
2011^{18}\end{array}$ & $\begin{array}{l}\text { Dakar, } \\
\text { Senegal }\end{array}$ & $\begin{array}{l}\text { Cross- } \\
\text { sectional } \\
\text { study }\end{array}$ & $\begin{array}{l}70 \\
\text { pasien } \\
\text { pria }\end{array}$ & $\begin{array}{l}\text { Tidak ada perbedaan yang signifikan } \\
\text { antara diuretik }(\mathrm{p}=0.20) \text { dan } \beta \text {-blocker } \\
(\mathrm{p}=0.37) \text {. }\end{array}$ \\
\hline & $\begin{array}{l}\text { Sarma AV, } \\
2019^{19}\end{array}$ & $\begin{array}{l}\text { Ann Arbor, } \\
\text { Michigan }\end{array}$ & Cohort study & $\begin{array}{l}692 \\
\text { pasien } \\
\text { pria }\end{array}$ & 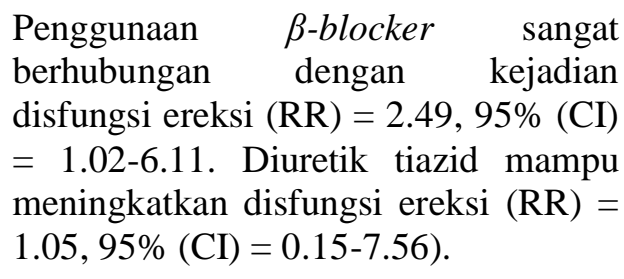 \\
\hline & $\begin{array}{l}\text { Artom N } \\
2015^{20}\end{array}$ & $\begin{array}{l}\text { Genoa, } \\
\text { Italia }\end{array}$ & Cohort study & $\begin{array}{l}270 \\
\text { pasien } \\
\text { pria }\end{array}$ & $\begin{array}{l}\beta \text {-blocker tidak meningkatkan } \\
\text { prevalensi disfungsi ereksi, 32 subjek } \\
\text { menunjukkan DE (50,8\%) dan } 31 \\
(49.2 \%) \text { fungsi seksual normal. } 18 \text { dari } \\
63 \text { subjek yang menggunakan } \beta \text { - } \\
\text { blocker menggunakan nebivolol } \\
(28.5 \%) \text {. }\end{array}$ \\
\hline & $\begin{array}{l}\text { Nathoo NA, } \\
2015^{21}\end{array}$ & $\begin{array}{l}\text { Vancouver, } \\
\text { Kanada }\end{array}$ & Case & $\begin{array}{l}13.800 \\
\text { pasien } \\
\text { pria }\end{array}$ & $\begin{array}{l}\text { Penggunaan } \beta \text {-blocker tidak memiliki } \\
\text { hubungan yang signifikan dengan } \\
\text { diagnosis disfungsi ereksi, rasio } 1.05 \\
\text { dan } 1.10 \text { ( } 95 \% \text { CI: } 0.61-1.99 \text { ). }\end{array}$ \\
\hline
\end{tabular}


Sebanyak 70 pasien pria yang didialisis berusia $>18$ (21-70) tahun dimasukkan pada penelitian Seck pada tahun 2011, menyatakan bahwa tidak ada perbedaan fungsi ereksi antara pasien dengan dialisis $<12$ jam / minggu dan pasien yang melakukan $>12$ jam / minggu. Faktor risiko klasik lainnya seperti diabetes, anemia, penyakit kardiovaskular, beberapa obat antihipertensi dan merokok. Tidak ada perbedaan yang signifikan antara pasien dengan disfungsi ereksi dan pasien yang tidak memiliki gangguan disfungsi ereksi setelah diberikan diuretik $(\mathrm{p}=0.20) .{ }^{18}$

\section{$\beta$-blocker}

Berdasarkan hasil dari penelitian literatur-literatur yang direview, menunjukkan bahwa 6 dari 9 literatur tidak terdapat pengaruh obat antihipertensi golongan $\beta$-blocker terhadap terjadinya disfungsi ereksi. Penelitian pada pasien dengan operasi bypass arteri koroner yang di berikan obat $\beta$-blocker (metoprolol dan nebivolol) menyatakan tidak memiliki pengaruh pada disfungsi ereksi. Penelitian Gur O pada tahun 2017 dengan jumlah sampel 119 pasien yang dibagi menjadi dua grup, insidensi disfungsi ereksi pada grup 1 (metoprolol) kejadian disfungsi ereksi derajat apapun $85.96 \%$ dan grup 2 (nebivolol) $83.87 \%$. perbedaan ini dianggap signifikan jika secara statistik $(\mathrm{p}=0.036) .{ }^{13}$ Penelitian Aldemir $\mathrm{M}$ pada tahun 2015 dengan 60 pasien yang memenuhi kriteria inklusi diacak dan dibagi menjadi dua kelompok: Kelompok $\mathrm{N}$, yang menerima $5 \mathrm{mg}$ nebivolol per oral selama 2 minggu sebelum pembedahan ditambah 12 minggu setelah pembedahan atau kelompok $\mathrm{M}$, yang menerima $50 \mathrm{mg}$ metoprolol per oral untuk periode yang sama. Semua pasien dievaluasi oleh domain fungsi ereksi dari Indeks Internasional Fungsi Ereksi-5 (IIEF-5) pada saat masuk (sebelum memulai $\beta$-blocker) dan 3 bulan setelah operasi. Pada kelompok metoprolol, rerata skor IIEF-5 menurun secara signifikan dari baseline 15,2 $\pm 5,8$ menjadi $12,9 \pm 5,8(\mathrm{p}<0,001)$, tetapi pada kelompok nebivolol, perbedaan ini tidak signifikan (dari baseline 12,9 \pm 5,5 menjadi $12,4 \pm 5,5, \mathrm{p}=0,053)$. Pada semua pasien, rata-rata skor IIEF-5 menurun secara signifikan dari baseline 14,0 $\pm 5,7$ menjadi $12,6 \pm 5,6(\mathrm{p}<0,001) .{ }^{14}$

Penelitian Yang L tahun 2013 pada 218 pasien dengan hipertensi yang tidak diobati menggunakan obat antihipertensi kombinasi antara felodipine dan metoprolol. Total skor IIEF pada kelompok $\mathrm{F}+\mathrm{M}$ tidak berbeda secara signifikan pada minggu ke $48 \quad(p=0.758)$. Tidak ada perubahan signifikan yang diamati pada skor domain untuk fraksi ereksi, fungsi orgasme, hasrat seksual, kepuasan seksual atau kepuasan keseluruhan faksi dalam kelompok $\mathrm{F}+\mathrm{M} \quad(\mathrm{p}>0.05)$. penelitian ini menunjukkan bawah felodipine yang dikombinasikan dengan metoprolol memiliki efek yang sama pada penurunan tekanan darah. ${ }^{15}$

Hasil dari penelitian Seck SM tahun 2011 pada 70 pasien tidak memiliki pengaruh antara pasien disfungsi ereksi dan pasien yang tidak memiliki gangguan disfungsi ereksi dengan pemberian obat $\beta$ blocker. Penelitian Artom tahun 2015 menyatakan juga bahwa penggunaan $\beta$ blocker tidak meningkatkan prevalensi disfungsi ereksi, dari 63 pasien hipertensi yang menggunakan $\beta$-blocker, sebanyak 32 pasien menunjukkan disfungsi ereksi (50.8\%) dan 31 (49.2\%) fungsi seksual normal tanpa ada perbedaan yang signifikan. $^{18}$

Penelitian Nathoo NA tahun 2015 pada 13.800 pasien usia 61 tahun menyatakan bahwa rasio tingkat kasar dari diagnosis disfungsi ereksi saat ini pada pasien setidaknya dengan 2 diagnosis untuk glaukoma adalah 1.34 dan bila untuk variabel penggunaan $\beta$-blocker oral, antihipertensi lain, dan berbagai komorbiditas. Penggunaan $\beta$-blocker topikal dalam 30 hari sebelum diagnosis disfungsi ereksi tidak memiliki hubungan yang signifikan dengan diagnosis disfungsi ereksi, dengan rasio perkiraan 1.05 dan rasio yang disesuaikan 1.10 (95\% CI: 0.611.99). ${ }^{21}$ 
Penelitian dari Mohammadi SZ tahun 2012 pada 100 pasien pria dengan gagal jantung sistolik dengan usia rata-rata 59 tahun menunjukkan bahwa disfungsi ereksi memiliki hubungan dengan obat antihipertensi $\beta$-blocker. Hasil dari penelitian Steinke EE tahun 2015 pada 149 pasien pria dengan usia rata-rata 66 menunjukkan $\beta$-blocker generasi pertama dan ketiga mempengaruhi aktivitas seksual secara merugikan. Pasien yang menggunakan $\beta$-blocker generasi pertama adalah pasien yang melakukan hubungan seks lebih jarang daripada sebelumnya atau tidak aktif secara seksual dan $\beta$-blocker generasi ketiga memiliki berbagai tingkat aktivitas seksual, tetapi sebagian besar berhubungan seks lebih jarang daripada sebelum diagnosis jantung. ${ }^{16}$

Penelitian Sarma AV tahun 2019 pada 692 pasien yang berusia 19- 50 tahun, 451 laki-laki menunjukkan bahwa risiko disfungsi ereksi meningkat dengan penggunaan obat antihipertensi dan obat antihipertensi yang sangat berhubungan dengan risiko kejadian disfungsi ereksi adalah $\beta$-blocker. Kejadian disfungsi ereksi cukup signifikan lebih besar pada pria yang melaporkan menggunakan obat antihipertensi. ${ }^{19}$

\section{SIMPULAN}

Obat antihipertensi golongan diuretik dan $\beta$-blocker memiliki pengaruh terhadap disfungsi ereksi. Obat antihipertensi golongan diuretik lebih berpengaruh terhadap disfungsi ereksi dibandingkan dengan obat antihipertensi golongan $\beta$ blocker.

\section{Konflik Kepentingan}

Penulis menyatakan tidak terdapat konflik kepentingan dalam studi ini.

\section{DAFTAR PUSTAKA}

1. Tendean L, Wantouw B. Penanganan Disfungsi Ereksi Secara Dini. Jurnal Kedokteran Komunitas dan Tropis. 2015;3(3):196-9.

2. Sasube N, Rampengan SH. Disfungsi ereksi pada penyakit kardio- vaskular. Jurnal Biomedik. 2016; 8:8-16.

3. Ghofar A, Ashari A. Hubungan Antara Penyakit Sistemik Pada Lansia Pria Dengan Disfungsi Ereksi. Jurnal EduHealth. 2010;1(1):4755.

4. Aita G, Da Ros CT, Lorenzini F, Bertero EB, Cairoli CE, Tustumi F, et al. Erectile dysfunction: Drug treatment. Rev Assoc Med Bras. 2019;65(9):1133-42.

5. Berookhim BM, Mulhall JP. Erectile Dysfunction. In: Sidawy AN, Perler BA, eds. Rutherford's Vascular Surgery and Endovascular Therapy, 9 ed. Philadelphia, PA: Elsevier Inc.; 2019.

6. Noverio Tarukallo. Anti-Hypertensive Drugs and Sexual Dysfunction in Men. Jurnal Ilmu Kesehatan. 2020;13:1-11.

7. Manolis A, Doumas M. Antihypertensive treatment and sexual dysfunction. Curr Hypertens Rep. 2012;14(4): 285-92.

8. Bongkriwan M, Wantouw B, Satiawati L. Pengaruh Pekerjaan Koki Dengan Terjadinya Disfungsi Ereksi. e-Biomedik 2014;2(2): 519-22.

9. Swerdloff RS. Male Sexual Function and Its Disorders: Physiology, Pathophysiology, Clinical Investigation, and Treatment. 2015;22(April): 342-88.

10. Feldman HA, Goldstein I, Hatzichristou DG, Krane RJ, McKinlay JB. Impotence and its medical and psychosocial correlates: results of the Massachusetts Male Aging Study. The Journal of Urology 1994;151(1):54-61.

11. McMahon CG. Erectile dysfunction. Intern Med J. 2014;44(1):18-26.

12. Joseph P, Lonn E, Bosch J, Lopez P, Zhu J, Keltai M, et al. Long-term Effects of Statins, Blood PressureLowering, and Both on Erectile Function in Persons at Inter- 
mediate Risk for Cardiovascular Disease: A Substudy of the Heart Outcomes Prevention Evaluation3 (HOPE-3) Randomized Controlled Trial. Can J Cardiol 2018;34(1):38-44.

13. Gür Ö, Gurkan S, Yumun G, Turker P. The comparison of the effects of nebivolol and metoprolol on erectile dysfunction in the cases with coronary artery bypass surgery. Ann Thorac Cardiovasc Surg. 2017;23(2):91-5.

14. Aldemir M, Keleş İ, Karalar M, Tecer E, Adalı F, Pektaş MB, et al. Nebivolol compared with metoprolol for erectile function in males undergoing coronary artery bypass graft. Anatol J Cardiol. 2016;16(2):131-6.

15. Yang L, Yu J, Ma R, Zhao F, Lin X, Liu $P$, et al. The effect of combined antihypertensive treatment (felodipine with either irbesartan or metoprolol) on erectile function: A randomized controlled trial. Cardiol. 2013;125 (4):235-41.

16. Mohammadi SZ, Shahparian M, Fahidy F, Fallah E. Sexual dysfunction in males with systolic heart failure and associated factors. ARYA Atheroscler. 2012;8(2):63-9.

17. Steinke EE, Mosack V, Hill TJ. Change in sexual activity after a cardiac event: The role of medications, comorbidity, and psychosocial factors. Appl Nurs Res. 2015;28 (3):244-50

18. Seck SM, Dahaba M, Diouf B, Cisse MM, Gueye S, Ka EF, et al. The burden of erectile dysfunction in dialysis patients in Senegal. Hemodial Int. 2011;15(2):280-3.

19. Sarma A V, Hotaling JM, De Boer IH, Dunn RL, Oerline MK, Singh K, et al. Blood pressure, antihypertensive medication use, and risk of erectile dysfunction inmenwith type Idiabetes. J Hypertens. 2019;37(5):1070-6.

20. Artom N, Pinna G, Musso NR, Orlandini F, Malasoma P, Uccelli $M$, et al. Prevalence of erectile dysfunction in a cohort of Italian hypertensive subjects. Clin Exp Hypertens. 2016;38(2):143-9.

21. Nathoo NA, Etminan M, Mikelberg FS. Association between glaucoma, glaucoma therapies, and erectile dysfunction. J Glaucoma. 2015;24 (2):135-7. 